\title{
Genetic testing and counseling of a recipient after bone marrow transplant from a sibling harboring a germline BRCA1 pathogenic mutation
}

\author{
PETRA ŠKERL ${ }^{1}$, MATEJA KRAJC ${ }^{2}$, ANA BLATNIK $^{2}$ and SRDJAN NOVAKOVIĆ ${ }^{1}$ \\ ${ }^{1}$ Department of Molecular Diagnostics and ${ }^{2}$ Cancer Genetics Clinic, Institute of Oncology Ljubljana, 1000 Ljubljana, Slovenia
}

Received March 22, 2017; Accepted May 9, 2017

DOI: $10.3892 /$ or.2017.5703

\begin{abstract}
Allogenic bone marrow transplant recipients represent a unique challenge, when they are referred for genetic testing and counseling. When performing genetic testing, it is extremely important to ensure that the detected DNA mutations originate from the patients own DNA, and therefore the most appropriate and reliable biological sample for DNA isolation must be obtained. The aim of the present study was to present the germline testing and counseling approach utilized in a rare case of a chimeric woman who received an allogenic bone marrow transplant from a sibling with a germline BRCA1 pathogenic mutation. According to our results, hairs with follicles are a reliable and ready source of DNA in a patient whose blood is of allogenic bone marrow transplant donor origin. Compared with a fibroblast culture, which is more difficult to obtain, the hair follicles are much more accessible and hair sampling is less invasive for the patient. Genetic testing based on the other sources of DNA, such as buccal swabs, is questionable due to the known risk of donor DNA contamination.
\end{abstract}

\section{Introduction}

Allogeneic bone marrow transplant is an effective treatment for many advanced and high-risk hematological malignancies (1). During the procedure, the hematopoietic and immune system of the recipient is destroyed by chemotherapy or radiotherapy, followed by the administration of hematopoietic stem cells harvested from the donor. Hematopoietic stem cells of the donor engraft, proliferate, and finally reconstitute hematopoiesis in the recipient. Thus, white blood cells from allogeneic bone marrow transplant (allo-BMT) recipients are usually entirely derived from the bone marrow of the donor (1). According to National Comprehensive Cancer Network

Correspondence to: Professor Srdjan Novaković, Department of Molecular Diagnostics, Institute of Oncology Ljubljana, Zaloška 2, 1000 Ljubljana, Slovenia

E-mail: snovakovic@onko-i.si

Key words: allogenic bone marrow transplant, chimeric DNA, genetic testing, genetic counseling
(NCCN) guidelines, the DNA of allo-BMT recipients should be extracted from a fibroblast culture derived from skin fibroblasts of the allo-BMT recipients, when available. When this is not possible, buccal cells may be considered as an alternative source for DNA (2). Since various studies have reported that over time, buccal epithelial cells are replaced by donor-derived cells in allo-BMT recipients $(3,4)$, molecular genetic testing in allo-BMT patients performed using DNA derived from blood as well as from buccal samples may reflect the genetic status of the transplant donor and not the recipient. For genetic counseling it is extremely important to ensure that detected DNA variants (mutations) reflect the germline DNA of the patient, since they impact the subsequent clinical management of the patient and his/her family members (5). Therefore, biological samples other than blood or buccal swabs should be considered for DNA isolation.

The aim of the present study was to present the germline testing and counseling approach utilized in a rare case of a chimeric donor-related BRCA1-positive woman who received an allogenic bone marrow transplant from a sibling with a germline $B R C A 1$ pathogenic mutation.

\section{Patient and methods}

Ethical approval and consent to participate. All tested family members provided written informed consent to participate and attended genetic counseling sessions before and after testing. A copy of the written consent can be obtained by contacting the authors of the present study. Genetic counseling and testing at the Institute of Oncology Ljubljana was approved by the Commission for Medical Ethics at the Ministry of Health, Republic of Slovenia in 1999.

Case and family presentation. The patient we are presenting is a 50-year-old female, who approached our clinic, since her non-identical twin sister had been diagnosed with breast cancer at the age of 49 and her older sister had been diagnosed with bilateral breast cancer (at age 47 and 52). Her mother and maternal aunt had also been diagnosed with cancer (liver cancer, at the age of 52 and ovarian cancer at the age of 50, respectively), and on her father's side of the family, there were cases of lung and bladder cancer (Fig. 1).

A genetic test was first performed in her older sister (diagnosed with bilateral breast cancer), who was identified as a 


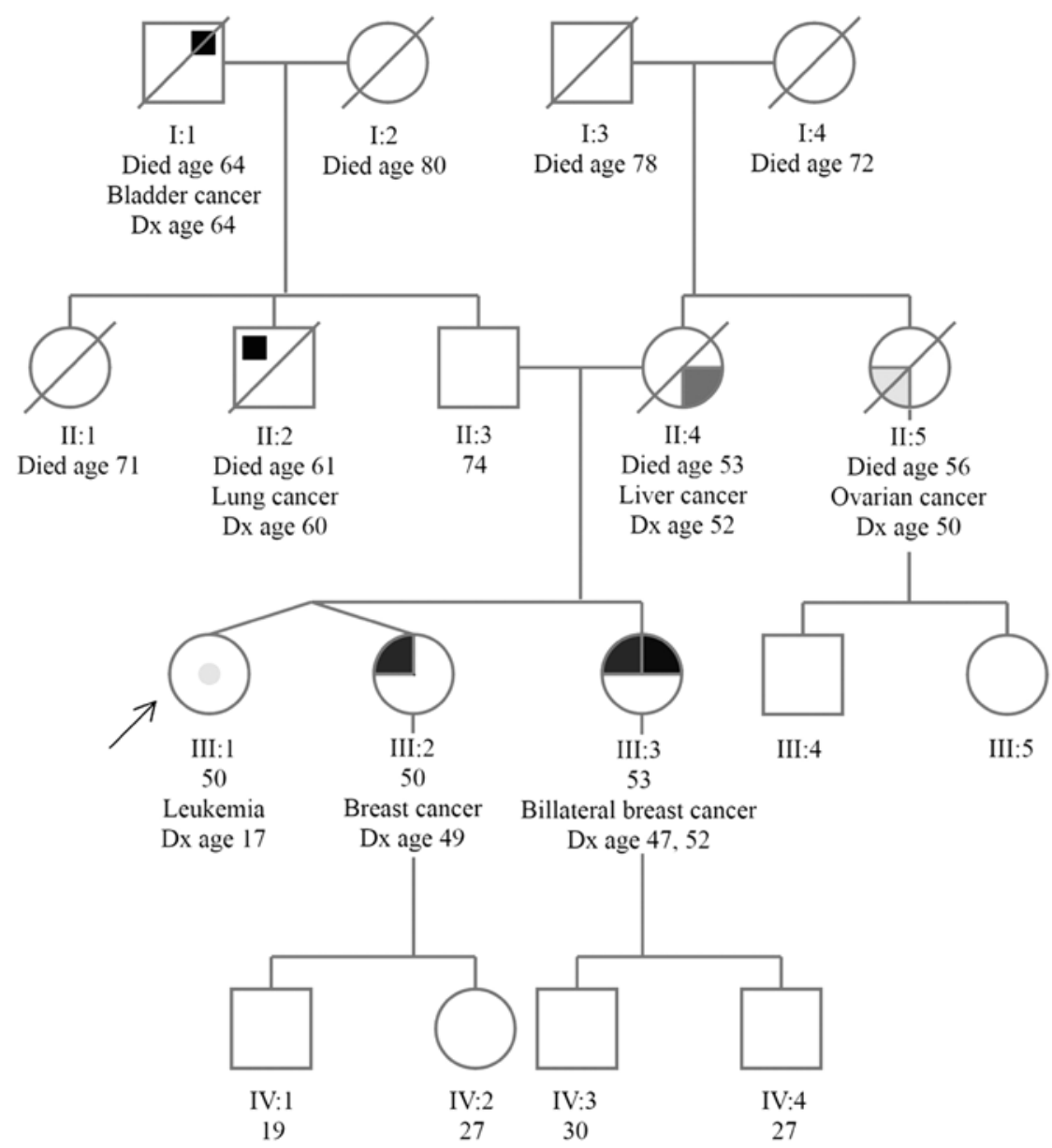

Figure 1. Pedigree of the family. The black arrow indicates our allo-BMT patient. Dx, diagnosed.

carrier of BRCA1 mutation. Subsequently, genetic testing for a known family $B R C A 1$ pathogenic mutation was performed in her twin sister (diagnosed with breast cancer), who was identified as a carrier of a known family BRCAl pathogenic mutation.

At the pre-test counseling session, the patient informed her consultant that she had been diagnosed with chronic myeloid leukemia (CML), Ph1-positive, at the age of 17 (in 1984) and that she had been systemically treated over the next 8 years. At the age of 25, she was still in the first chronic phase of CML, and her older sister was found to be a human leukocyteassociated antigen (HLA) identical and mixed lymphocyte culture (MLC) non-reactive donor. Hence, allogeneic bone marrow transplantation was performed with her older sister's marrow stem cells in 1992. Since then, she has been on yearly follow-up.

The BRCA test result was of great importance for our patient, since in the case of a positive result, she may be eligible for high risk screening and may be offered preventive surgeries for breast and ovarian cancer at our institution. In contrast, in the case her test result is negative, she may be relieved of a great psychological burden and may be enrolled in a national breast cancer screening programme.

Sample collection, DNA extraction and sequencing. All tested family members provided written informed consent and attended genetic counseling sessions before and after testing.
In the case of our patient, three different types of biological samples were obtained: peripheral blood, buccal swabs and 5-7 plucked head hair samples.

Blood samples were collected in EDTA-tubes, and DNA was extracted using QIAamp DNA Blood Mini kit (Qiagen, Hilden, Germany) according to the manufacturer's instructions.

Buccal swab sampling was performed by softly brushing the mucosal cheek using a cotton swab (ForensiX SafeDry Evidence Collection Tube; Prionics AG, Schlieren-Zürich, $\mathrm{CH}$, Switzerland). DNA was extracted using QIAamp DNA Blood Mini kit according to the manufacturer's instructions for buccal swabs.

Five to seven full-length hairs with follicles were placed into one $1.5-\mathrm{ml}$ tube. The presence of a hair follicle was visually confirmed. Hairs were cut into $\sim 1 \mathrm{~cm}$ including the follicle, and the distal part was discarded. Buffer ATL and proteinase $\mathrm{K}$ (both from Qiagen) were added and tubes were incubated overnight at $56^{\circ} \mathrm{C}$ with shaking at $900 \mathrm{rpm}$. DNA was extracted using QIAamp DNA Blood Mini kit according to the manufacturer's instructions with a modification including additional incubation with $\mathrm{AL}$ buffer (Qiagen) at $70^{\circ} \mathrm{C}$ for 10 min after overnight incubation.

DNA quality and quantity of all samples were spectrophotometrically evaluated using NanoDrop 1000 spectrophotometer (Thermo Fisher Scientific, Inc., Waltham, MA, USA).

Genetic testing for a known family BRCA1 (LRG_292t1) pathogenic mutation c.5266dupC p.(Gln1756Profs*74) was 

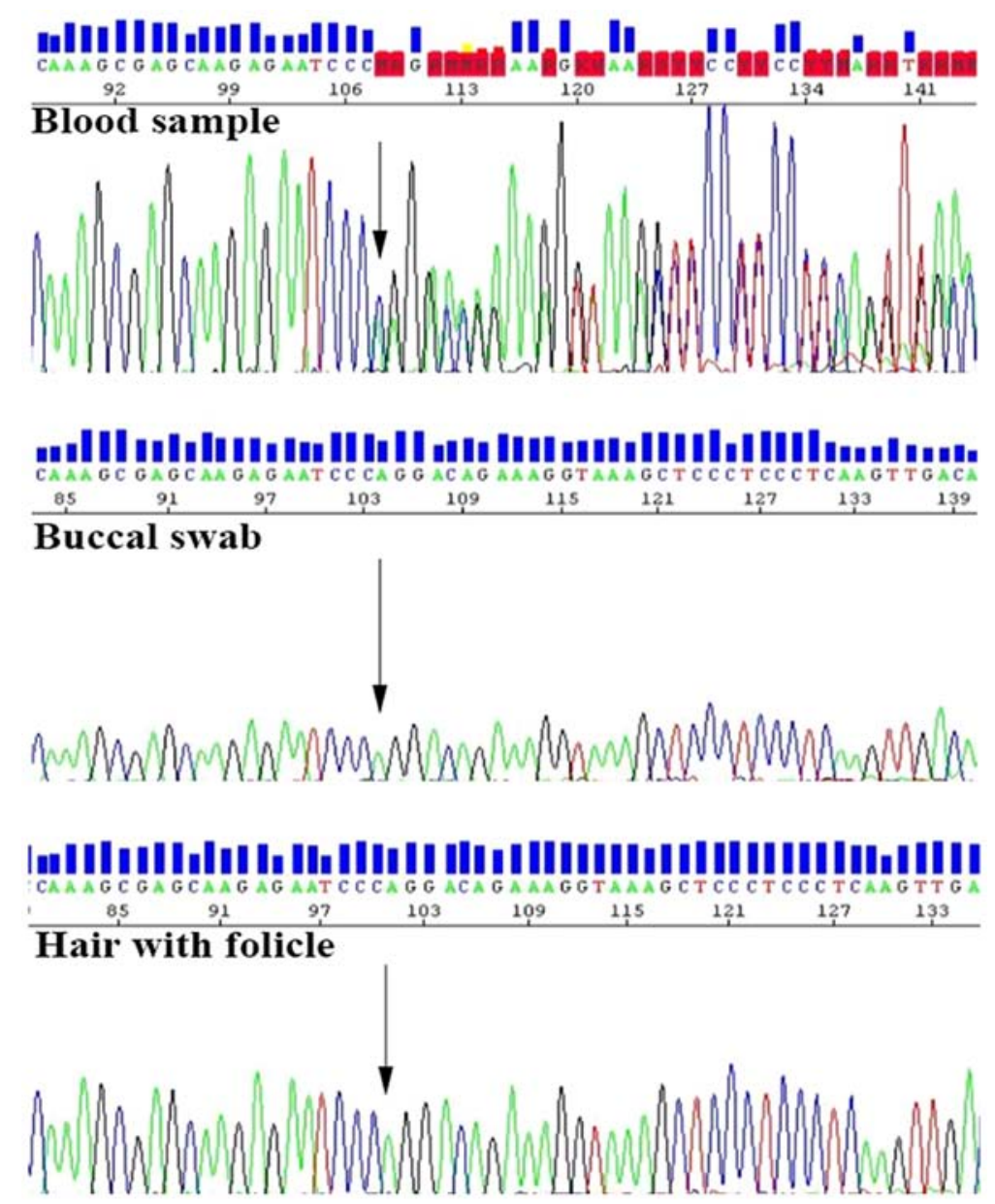

Figure 2. Sequencing analysis results of DNA samples isolated from the blood, buccal swab and hair with follicle obtained from our allo-BMT patient. Electropherograms show the position (indicated with black arrows) of a BRCA1 mutation c.5266dupC p.(Gln1756Profs*74).

performed by Sanger sequencing on the ABI3500 sequencer (Applied Biosystems, Foster City, CA, USA) as previously described $(6,7)$. All results were confirmed by the analysis of an independent second DNA sample obtained from blood, buccal swab and hair.

\section{Results and Discussion}

In the present study, we studied a rare case of a woman with a prior history of leukemia, who received an allogenic bone marrow transplant 25 years ago from a sibling harboring a germline BRCA1 pathogenic mutation c.5266dupC p.(Gln1756Profs*74). At the time of allo-transplantation the donor (sister) was healthy and unaware of having a $B R C A$ mutation.

When an allo-BMT recipient requires genetic testing, the first question that arises is what may be the appropriate and reliable biological sample for DNA isolation. For a long-time it was believed that, in contrast to blood cells which may often be replaced by those with the donor genotype, other cells remain of recipient origin (3). Recently, bone marrow and peripheral blood stem cells have been noted to have the potential to transdifferentiate or dedifferentiate into neural, bone, muscular, cartilage, liver, gut, alveolar, buccal, epidermal or endothelial cells. This process is called 'adult stem cell plasticity phenomenon'. The frequency of appearance of these exogenous cells is reported to be between 0.1 and $10 \%$ of tissue-specific cells (8-12).

Tran et al (4) were the first to report that allogenic human bone marrow-derived cells migrate into the cheek and differentiate into epithelial cells. Since it was reported that over time, buccal epithelial cells of the recipient could be replaced by donor-derived cells, genetic testing based on DNA isolated from buccal swab samples has become questionable given this known risk of donor DNA contamination (4). Therefore, in allo-BMT recipients. other sources of DNA should also be considered. It has been shown that hair follicles lack adult stem cell plasticity and remain of recipient origin for more than 20 years after allogenic hematopoietic stem cell transplantation (3). Taking into account all of these facts, we collected peripheral blood, buccal swabs and 5-7 plucked head hair samples in our case of an allo-BMT recipient. The sequencing analysis of the DNA sample isolated from her blood showed a positive result for a known family BRCAl mutation c.5266dupC p.(Gln1756Profs*74). However, the DNA samples extracted from her buccal swab and hair were negative for this mutation (Fig. 2). According to the results of genetic testing, she was found not to be a carrier of a germline $B R C A 1$ pathogenic mutation known in her family, but she represents a chimeric donor-related $B R C A 1$-positive carrier. At the post-test genetic counseling session she was advised to take part in the national breast cancer screening programme, 
where mammographies are performed every two years (for women between 50-69 years). She is also followed up yearly for CML.

In our case, the genetic testing strategy was greatly facilitated since the BRCAl mutation was known in this family [c.5266dupC p.(Gln1756Profs*74)]. Therefore, the genetic testing from blood was expected to be positive for a known family mutation. To determine whether the mutation was of germline origin, other DNA sources were successfully used. In the 'vice versa' situation, when the bone marrow donor is negative for a known family mutation, a false-negative result could be reported, when additional sources of DNA are not tested.

An additional question that arises from these results is what cancer risk is expected for such chimeric donor-related BRCAl carriers. Notably, after the allogenic bone marrow transplant, our 50-year-old allo-BMT recipient has not been diagnosed with breast or ovarian cancer or any hematologic malignancies. As mentioned previously, bone marrow and peripheral blood stem cells transdifferentiate into different types of cells including buccal, epidermal or endothelial cells. However, to the best of our knowledge, there are no data in the literature clearly describing the risk for breast or ovarian cancer in $B R C A$-negative patients receiving $B R C A$-positive allogenic bone marrow transplants. There are several studies supporting the hypothesis that $B R C A 1$ mutations affect the development of hematologic malignancies through defective DNA repair pathways (13). There is an evident increase in the risk of hematologic malignancies in patients with a detected mutation in genes involved in the BRCA pathway, including mantle cell lymphoma, acute myeloid, acute and chronic lymphocytic and prolymphocytic leukemia (14). Various epidemiologic studies have also found increased risks for leukemia and lymphoma in identified BRCA1/BRCA2 mutation carriers $(15,16)$. Unfortunately, there are no studies of a possible risk for a second hematologic malignancy for chimeric donor-related $B R C A l$ carriers with a prior history of leukemia. The significance of a donor-related $B R C A l$ mutation in such carriers should be further evaluated. Therefore, careful genetic counseling and follow-up for such patients should be considered.

In conclusion, according to our results and a study mentioned above, hairs with follicles are a reliable and ready source of DNA as they appear to be completely of allo-BMT recipient origin. Compared with a fibroblast culture, which is more difficult to obtain, the hair follicles are much more accessible and hair sampling is less invasive for the patient. Evaluation of the family history is important before a bone marrow transplant, and patients who fulfill the criteria for genetic testing may be referred for genetic counseling before a bone marrow transplant. Since the family history can be unremarkable at the time of transplantation, blood or DNA samples from all allo-BMT patients must be routinely stored in case they are needed for future genetic testing.

\section{Acknowledgements}

The authors would like to thank Simona Traven for her substantial laboratory technical assistance. We are grateful to the family for participation. The present study was partially supported by the Slovenian Research Agency (grant no. P3-0352).

\section{References}

1. Waterhouse M, Themeli M, Bertz H, Zoumbos N, Finke J and Spyridonidis A: Horizontal DNA transfer from donor to host cells as an alternative mechanism of epithelial chimerism after allogeneic hematopoietic cell transplantation. Biol Blood Marrow Transplant 17: 319-329, 2011.

2. Network NCCN: NCCN Clinical Practice Guidelines in Oncology - Genetic/Familial high-risk assessment: Breast and ovarian. Version 2016: 2016.

3. Hong YC, Liu HM, Chen PS, Chen YJ, Lyou JY, Hu HY, Yi MF, Lin JS and Tzeng CH: Hair follicle: A reliable source of recipient origin after allogeneic hematopoietic stem cell transplantation. Bone Marrow Transplant 40: 871-874, 2007.

4. Tran SD, Pillemer SR, Dutra A, Barrett AJ, Brownstein MJ, Key S, Pak E, Leakan RA, Kingman A, Yamada KM, et al: Differentiation of human bone marrow-derived cells into buccal epithelial cells in vivo: A molecular analytical study. Lancet 361: 1084-1088, 2003.

5. Mancini-DiNardo D, Landon M, Abbott B, Elias M, Rinsky J and Roa B: Complexities in genetic testing for allogenic bone marrow transplant recipients and patients with hematologic malignancies. Journal 2016: 2014. http://www.ashg.org/2014meeting/abstracts/ fulltext/f140122408.htm.

6. Novaković S, Milatović M, Cerkovnik P, Stegel V, Krajc M, Hočevar M, Zgajnar J and Vakselj A: Novel BRCA1 and BRCA2 pathogenic mutations in Slovene hereditary breast and ovarian cancer families. Int J Oncol 41: 1619-1627, 2012.

7. Stegel V, Krajc M, Zgajnar J, Teugels E, De Grève J, Hočevar M and Novaković S: The occurrence of germline BRCAl and $B R C A 2$ sequence alterations in Slovenian population. BMC Med Genet 12: 9, 2011.

8. Jiang Y, Jahagirdar BN, Reinhardt RL, Schwartz RE, Keene CD, Ortiz-Gonzalez XR, Reyes M, Lenvik T, Lund T, Blackstad M, et al: Pluripotency of mesenchymal stem cells derived from adult marrow. Nature 418: 41-49, 2002.

9. Körbling M, Katz RL, Khanna A, Ruifrok AC, Rondon G, Albitar M, Champlin RE and Estrov Z: Hepatocytes and epithelial cells of donor origin in recipients of peripheral-blood stem cells. N Engl J Med 346: 738-746, 2002.

10. Krause DS, Theise ND, Collector MI, Henegariu O, Hwang S, Gardner R, Neutzel S and Sharkis SJ: Multi-organ, multi-lineage engraftment by a single bone marrow-derived stem cell. Cell 105: 369-377, 2001.

11. Mezey E, Chandross KJ, Harta G, Maki RA and McKercher SR: Turning blood into brain: Cells bearing neuronal antigens generated in vivo from bone marrow. Science 290: 1779-1782, 2000.

12. Orlic D, Kajstura J, Chimenti S, Jakoniuk I, Anderson SM, Li B, Pickel J, McKay R, Nadal-Ginard B, Bodine DM, et al: Bone marrow cells regenerate infarcted myocardium. Nature 410: 701-705, 2001.

13. Kim HS, Lee SW, Choi YJ, Shin SW, Kim YH, Cho MS, Lee SN and Park KH: Novel germline mutation of BRCAl gene in a 56-year-old woman with breast cancer, ovarian cancer, and diffuse large B-cell lymphoma. Cancer Res Treat 47: 534-538, 2015.

14. Friedenson B: The BRCA1/2 pathway prevents hematologic cancers in addition to breast and ovarian cancers. BMC Cancer 7: $152,2007$.

15. Risch HA, McLaughlin JR, Cole DE, Rosen B, Bradley L, Kwan E, Jack E, Vesprini DJ, Kuperstein G, Abrahamson JL, et al: Prevalence and penetrance of germline BRCA1 and BRCA2 mutations in a population series of 649 women with ovarian cancer. Am J Hum Genet 68: 700-710, 2001.

16. Shih HA, Nathanson KL, Seal S, Collins N, Stratton MR, Rebbeck TR and Weber BL: BRCA1 and BRCA2 mutations in breast cancer families with multiple primary cancers. Clin Cancer Res 6: 4259-4264, 2000. 